\title{
Determinant Factors of Student Procrastination Behavior of Technical and Vocational Teacher Education
}

\author{
Nunuk Hariyati \\ Department of Educational Management \\ Universitas Negeri Surabaya \\ Surabaya, Indonesia \\ nunukhariyati@unesa.ac.id
}

\author{
Tarma \\ Department of Home Economics Education \\ Universitas Negeri Jakarta \\ Jakarta, Indonesia \\ tarma@unj.ac.id
}

\begin{abstract}
Teachers are required to have a good ability to manage tasks. Teacher education must develop the ability to manage tasks on the students themselves. Procrastination is a problematic behavior undertaken by students of vocational teacher education. This study aims to measure the contribution of information literacy, emotional regulation and self-directed learning on the behavior of procrastination. Research conducted in December 2016 at the Faculty of Engineering, State University of Jakarta with 341 respondents from various departments. The method used quantitative descriptive survey approach. The research found that: (1) the correlation coefficient between the information literacy with procrastination behavior is $\mathbf{- 0 . 1 9 2}$ (negative correlation); (2) the correlation coefficient between emotional regulation with procrastination behavior is $\mathbf{- 0 . 1 9 2}$ (negative correlation); and (3) the correlation coefficient between self-directed learning with procrastination behavior is $\mathbf{- 0 . 2 7 9}$ (negative correlation). The correlation between the information literacy with self-directed learning at 0.645 and the correlation between emotional regulation with self-directed learning at 0.551 . Variable information literacy contributes to procrastination behavior $4 \%$. Variable emotional regulation contributes to procrastination behavior $4 \%$. Variable self-directed learning contributes to procrastination behavior by $8 \%$. Based on these findings, the intervention variable information literacy, emotional regulation and self-directed learning can reduce procrastination behavior problems in students of vocational teacher education. So as to suppress the behavior of procrastination, college LPTK need to develop a program to improve information literacy, emotional regulation and selfdirected learning in students.
\end{abstract}

Keywords-information literacy, emotional regulation, selfdirected learning, procrastination behavior

\section{INTRODUCTION}

The teacher must have the ability to manage the job well. Work as a teacher has many tasks, such as planning lessons, carrying out teaching, doing learning evaluations, doing classroom-based research, coaching students, and developing schools. To be able to manage the teacher's tugaa well, the teacher education student must have good ability about managing the task, have the ability of time management, have the ability to set priority, and do the job well. Tasks that are carried out at the end of time have an impact on the quality of poor work outcomes.

Many behavioral problems in teacher education students. One of them is the habit of doing the task at the end of time. So the poor quality papers or project students. The habit of delaying such work in behavioral science is known as procrastination. This study measures the procrastination behavior in students of vocational teacher education program. In addition, this study also revealed the determinants of procrastination behavior in students.

Many variables are the determinants of procrastination behavior. Factors affecting procrastination's divided into four major sections: task characteristics, individual differences, outcomes, and demographics [1]. Task characteristics indicate possible environmental causes of procrastination. The section on individual differences deals with relevant personality traits and is organized into the traditional five-factor model. Outcomes indicate the proximal effects of procrastination. Finally, the section on demographics reviews possible physical and cohort moderators. Each section is then subdivided into more specific constructs, which are reviewed along with their relevant theory. The relationships covered are then subsequently considered in the meta-analytic review. In this study, determinant factors that are expected to affect procrastination are the ability of information literacy, selfdirected learning, and emotional regulation.

Information literacy is generally interpreted as literacy or information literacy. According to the English Dictionary, the word "literacy" means the ability to read information. So the information literacy is the literature of information. Information literacy is a set of abilities requiring individuals to recognize when information is needed and have the ability to locate, evaluate, and use effectively the needed information [2]. Campbell describes several standards of information literacy capabilities, include: (1) recognize information needs; (2) locate and evaluate the quality of information; (3) store and retrieve information; (4) make effective and ethical use of information; and (5) apply information to create and communicate knowledge. According to Association of College \& Research Libraries (ACRL), there are five standards of information literacy, namely: (1) determines the nature and 
extent of the information needed; (2) accesses needed information effectively and efficiently; (3) evaluates information and its sources critically and incorporates selected information into his or her knowledge base and value system; (4) uses information effectively to accomplish a specific purpose; and (5) understands many of the economic, legal, and social issues surrounding the use of information and accesses and uses information ethically and legally.

Students' inability to manage emotions can lead to student procrastination behavior. Students need to have the ability to manage their emotions to succeed academically. Emotion regulation is how individuals change their emotional experience to make it more manageable [3]. Multidimensional model conceptualizes emotion regulation as adaptive responses to emotional distress (vs. efforts to control or suppress emotional arousal), and is characterized by four dimensions: (a) flexible use of adaptive strategies to modulate (vs. eliminate) the intensity and/or temporal features of an emotional response; (b) ability to resist impulsive behaviors and engage in goaldirected behaviors in the context of emotional distress; (c) emotional awareness, clarity, and acceptance; and (d) willingness to experience emotional distress in the context of pursuing meaningful activities [4]

The ability to learn is not only determined by the quality of faculty and learning tasks given by the lecturers. Study time with lecturers is very limited. Students must have the ability to learn independently. To be successful academically, students must have the ability to learn independently. Independent learning disabilities can cause students difficulties in learning and cause students to do procrastination. The ability to learn independently is known as self-directed learning. Self-directed training includes the learner initiating the learning, making the decisions about what training and development experiences will occur, and how. The learner selects and carries out their own learning goals, objectives, methods and means to verify that the goals were met [5]. This study aims to measure: (1) the influence of information literacy on procrastination behavior; (2) the influence of self-directed learning on procrastination behavior; And (3) the effect of emotional regulation on procrastination behavior

\section{METHOD}

This research uses qualitative method by using survey technique. The population of this study are 3,320 student of vocational teacher education program, Faculty of Engineering, State Universities of Jakarta. The sample of this research is 341 students.

Data collection techniques using questionnaires. Measurement of emotional regulation variable using the ERQ (Emotional Regulation Questionnaire) that has been developed by Gross and John. Information literacy measurements using instruments developed by Campbell. Procrastination behavior using measurement instruments developed by Piers Steel. Selfdirected learning measurements using SDLRS (Self-Directed Learning Readiness Scale) developed by Guglierminos. The collected data is processed using correlation test using Pearson Product Moment and test of determination.

\section{RESULTS AND DISCUSSION}

Based on the results of the study, there are descriptions for each variable and the relationship between behavioral variables of procrastination, self-regulation, self-directed learning, and information literacy capability. Descriptions of each variable and the relationships among variables are described below.

\section{A. Procrastination Behavior}

The measurement of procrastination behavior uses a questionnaire with 20 items of statement. Based on the results of data processing is known maximum score of 70 , the minimum score is 27. Average score is 56.83. Student procrastination behavior is at the level of $56.83 \%$ of ideal. On a scale of $1-5$, the ability of new information literacy to reach 2.84. It shows that the ability of self-directed learning is still high category.

Based on the per-item analysis it is known that the lowest item score is delaying the work to do. It means that the student relatively does not delay the task. Meanwhile, the highest item is shown on an item about a long time to compose a paper, although it can actually be done in a short time. This suggests that the ability of the students in writing papers and arrange a time to prepare papers are still not optimal.

To reduce procrastination behavior, Edith Cowan University suggest 20 strategies. That strategies include Worstfirst approach, remember-forgetting technique, bits and pieces approach, break it down, five minute plan, positives and negatives, reward yourself, ask for help, pick your times, pick your times, establish priorities, manage time, change environment, minimize potential distractions, visible reminders, self-monitoring, talk self into it, set some goals, know thinking, and be persistent but patient. Other tips suggest by Center for Clinical Intervention to stop procrastination behavior, namely: worst-first, using momentum, just 5minutes, set time limits, prime time, prime place, rememberthen-do, reminders, visualize, focus, and plan rewards. To reduce student procrastination behavior, the campus needs to arrange training to train the skills to stop procrastination

\section{B. Information Literacy}

Measurement of information literacy using a questionnaire with 44 items statement. Based on the results of data processing known maximum score is 220 , the minimum score is 87. The average score is 146.64. Ability of student information literacy is at level $66,67 \%$ from ideal. On a scale of $1-5$, the literacy capability of new information reached 3.33. It shows that the ability of information literacy is still low.

Based on the per-item analysis it is known that the lowest item score is the ability to write articles and publish them in print. This shows that students' writing ability still needs improvement. Meanwhile the highest score item is the ability to use search engines when not knowing the reference website needed.

To increase information literacy, many effort needed. Collaborative efforts to improve information literacy, an intentional student learning outcome, were successful in enhancing the quality of research that students conducted. 
Utilizing three different instances of library assessment, the professor and librarians were able to see tangible results from the extra information literacy instruction [6].

To improve the information literacy capability, need to include the substance of information literacy there is a new student orientation period. In addition, the campus library should be more proactive in carrying out educational activities to improve information literacy. The campus library also needs to optimize services so that the library becomes an information center for students for academic needs.

\section{Emotional Regulation}

Measurement of emotional regulation using questionnaire with 10 items statement. Based on the results of data processing known maximum score is 50 , the minimum score is 24. Average score is 37.72 . The emotional regulation of student is at $75.44 \%$ level of ideal. On a scale of $1-5$, the emotional regulation reached 3.77 . It shows that the ability of emotional regulation is still moderate category.

Based on the analysis of the questionnaire peritem it was found that the lowest item score was trying to show the feeling of happiness. Meanwhile, the item with the highest score questionnaire is about the ability to maintain their own feelings.

To increase emotional regulation, Rolston and Richardson suggest several tips. The first tips is take care of physical needs. Getting a good night's rest, eating healthfully, and exercising your body are all essential to being able to feel satisfaction in life. We've all noticed how much better we can feel after having a good night of restful sleep or after eating a diet of healthy foods. It can be as though we have an entirely fresh perspective on life and it is much easier to overlook the little things that might have annoyed or upset us otherwise. Second, engage in activitiest hat build a sense of achievement. Doing one positive thing every day can lead to a sense of achievement and contentment. We can each benefit from paying more attention to the positive events in lives. The things that bring us joy have been shown to decrease negative moods and increase positive moods. Third, changing thoughts is easier than changing feelings. Thoughts play a critical role in how we experience a situation. When you notice yourself first becoming upset, try to evaluate what are thinking that is causing that emotion. Here are some questions to ask yourself: (1) what is it that's really pushing my buttons here?; (2) why am I reacting so strongly?; what's the worst (or best) that could happen?; (3) how important will this be tomorrow; next week? next month?

To improve the emotional regulation ability, the campus can develop activities such as optimizing guidance and counseling for students, include substance emission regulation in student orientation activities, and develop student activities based on maturity development and emotional intelligence

\section{Self-Directed Learning}

Measurements of self-directed learning using a questionnaire with 40 items of statement. Based on the results of data processing known maximum score of 200, the minimum score is 101. Average score is 151.39. The student's self-directed ability is at $75.70 \%$ of the ideal. On a scale of 1-5, the literacy capacity of the new information reached 3.78 . It shows that the ability of self-directed learning which is still moderate category.

Based on the results of the analysis peritem questionnaire about self-directed learning note that the item with the highest score is about feelings need to learn. Meanwhile, the scores of the lowest self-directed learning items are known on the item about the specific timing for learning.

To improve self-directed learning, Center For Teaching Excellence The University of Waterloo suggests the following stages. First, being ready to learn. Various skills and attitudes towards learning are required for successful independent study This step requires time for analysing a student's current situation, study habits, family situation, and support network both at school and at home - and as they continue in the program, progress in degree program and past units taken that will prove useful. Signs of readiness for self-directed learning include being: autonomous, organized, self-disciplined, able to communicate effectively, and able to accept constructive feedback and engage in self-evaluation and self-reflection. Second, setting learning goal.

Communication of learning goals between a student and the advising faculty member is critical. Learning contracts are highly recommended tools for successful self-directed learning experiences. Learning contracts generally include: goals for the unit of study, structure and sequence of activities, a timeline for completion of activities, details about resource materials for each goal, details about grading procedures, a section for advising faculty member feedback and evaluation as each goal is completed, and a plan for regular meetings with the advising faculty member and other unit policies, such as work turned in late. Third, students need to understand themselves as learners in order to understand their needs as self-directed learning students. Fourth, evaluating learning. Students must be able to engage in self-reflection and self-evaluation of learning goals and progress in a unit of study. Students should regularly consult with the advising faculty member. Students should be able to engage in self-validation of achievements, but should have the motivation to seek feedback on progress and ideas from the advising faculty member or other available resources.

\section{E. Determinan Factors of Procrastination Behavior}

Based on correlation test results among determinant variables known as follows. Correlation coefficient between the information literacy with procrastination behavior is -0.192 (negative correlation). Variable information literacy contributes to procrastination behavior $4 \%$. It means that behavior of high procrastination behavior caused by weakness of literacy ability, so that student find difficulties in finding, processing, compiling and writing information into the task. Correlation coefficient between emotional regulation with procrastination behavior is -0.192 (negative correlation). Variable emotional regulation contributes to procrastination behavior $4 \%$. It means that procrastination behavior is caused by weak emotional regulatory capabilities. To reduce the behavior of 
procrastination, the campus needs to intervene the program by increasing the ability of emotional regulation of student.

Correlation coefficient between self-directed learning with procrastination behavior is -0.279 (negative correlation). Variable self-directed learning contributes to procrastination behavior by $8 \%$. It means that the behavior of procrastination occurs because of the ability of self-directed learning students who still need to be improved. If students have high selfdirected learning ability, it will reduce procrastination behavior.

The correlation between the information literacy with selfdirected learning at 0.645 and the correlation between emotional regulation with self-directed learning at 0.551. Based on these findings, the intervention variable information literacy, emotional regulation and self-directed learning can reduce procrastination behavior problems in students of vocational teacher education.

\section{CONCLUSION}

Based on the findings and discussion of research results can conclude as follows. The literacy ability of information is negatively correlated with procrastination behavior. The higher the literacy capacity of information will lead to lower procrastination behavior. The emotional regulation ability is negatively correlated with procrastination behavior. The higher the emotional regulation ability of the students will lead to lower procrastination behavior. The ability of self-directed learning is negatively correlated with procrastination behavior. The higher the ability of self-directed learning in the students will lead to lower procrastination behavior. To reduce the behavior of procrastination can be done by intervention on increasing information literacy, emotional regulation, and selfdirected learning.

\section{REFERENCES}

[1] Steel, P. The Nature of Procrastination: A Meta-Analytic and Theoretical Review of Quintessential Self-Regulatory Failure. Psychological Bulletin. 2007, Vol. 133, No. 1, 65-94

[2] American Library Association. 2000. Information Literacy Competency Standards for Higher Education. Chicago, Illinois

[3] Leone, A.P., Gillespie, N. M., Orr, E. E., and Harrington, S.J. Measuring Subtypes of Emotion Regulation: From Broad Behavioural Skills to Idiosyncratic Meaning-making. Clinical Psychology and Psychotherapy. 2015.

[4] Gratz, K. L., \& Tull, M. T. (2010). Emotion regulation as a mechanism of change in acceptance-and mindfulnessbased treatments. In R. A. Baer (Ed.), Assessing mindfulness and acceptance: Illuminating the processes of change (pp. 107-134). Oakland, CA: New Harbinger.

[5] Chien, M.H., and Tsai, L. H. The Relationship Between Self-Directed Learning Readiness and Organizational Creativity Thinking Effectiveness. International Journal of Research In Social Sciences. 2015. Vol. 5, No.3, 65-71.

[6] Smith, Meggan D. and Amy B. Dailey. "Improving and Assessing Information Literacy Skills Through Faculty-Librarian Collaboration." College \& Undergraduate Libraries 20.3-4 (2013): 314-326. 